\title{
评述
}

\section{基于MOFs材料的非贵金属氧还原电催化剂研究 进展}

\author{
任子文 ${ }^{1}$, 谭泽昊 ${ }^{1}$, 向思䂞 ${ }^{1}$, 陈士渠 ${ }^{1}$, 沈水云 ${ }^{1,2^{*}}$, 章俊良 ${ }^{1,2^{*}}$ \\ 1. 上海交通大学机械与动力工程学院, 燃料电池研究所, 上海 200240 ; \\ 2. 上海交通大学动力机械与工程教育部重点实验室, 上海 200240 \\ *E-mail: shuiyun_shen@sjtu.edu.cn; junliang.zhang@sjtu.edu.cn \\ 收稿日期: 2021-04-15; 接受日期: 2021-05-10; 网络版发表日期: 2021-09-27 \\ 国家重点研发计划(编号: 2016YFB0101201)和国家自然科学基金(批准号: 21533005)资助项目
}

\begin{abstract}
摘要质子交换膜燃料电池(PEMFCs)因具有清洁、高效、安静、功率密度高、工作温度低、启动和功率匹配 快等优点在新能源汽车领域备受青睐。由于PEMFCs阴极使用高载量的铂 $(\mathrm{Pt})$ 基催化剂, 其成本一直居高不下, 大 大阻碍了燃料电池汽车商业化进程. 开发替代的高活性、高稳定性非贵金属催化剂被认为是终极解决方案. 在众 多类型的非贵金属催化剂中，碳-氮-过渡金属系列非贵金属催化剂表现出的ORR活性和寿命尤其值得关注. 基于 金属有机框架材料(MOFs)的非贵金属ORR电催化剂具有优异的性能而被广泛研究. 本文通过介绍MOFs材料的 特点与优势, 综述了近年来国内外基于 MOFs材料的碳-氮-过渡金属ORR电催化剂研究现状，主要包括Fe基MOFs 催化剂、Co基MOFs催化剂、双金属MOFs催化剂等, 并针对研究中遇到的瓶颈与挑战进行分析与展望, 指出未 来需要面向膜电极的活性、稳定性等进行深入研究.
\end{abstract}

关键词 燃料电池, 催化剂, 氧化, 金属有机框架化合物, 质子交换膜

\section{1 引言}

能源短缺、环境污染深刻影响着人类社会发展和 生态环境平衡 ${ }^{[1 ~ 3]}$. 随着经济、科技的发展, 新能源逐 渐成为各国研究的重点, 而在各类新能源技术中, 燃料 电池技术因转化效率高、环境友好、工作方式安静等 优点备受关注，尤其是低温质子交换膜燃料电池 (PEMFC)功率密度高、工作温度低、启动和功率匹配 快, 成为新能源汽车动力系统的重要发展方向. 与动力 锂离子电池相比, 燃料电池动力系统续驶里程长、加
氢时间短, 燃料电池汽车被认为是新能源汽车的终极 解决方案. 世界各大汽车公司于 20 世纪 90 年代便制定 了燃料电池汽车的开发计划, 并在近年逐渐实现量产 和实际应用. 2014年, 丰田推出了“MIRAI”燃料电池汽 车, 并于 2020 年发行了第二代, 其催化剂为低铂(Pt)合 金催化剂, 续航里程可达 $850 \mathrm{~km} .2016$ 年本田生产的第 三代Clarity汽车在大幅度提高性能的同时实现了轻量 化和小型化, 最大续航里程为 $750 \mathrm{~km}$. 韩国现代汽车于 2018年推出了新一代氢燃料电池车NEXO, 其最大功 率可达 $120 \mathrm{~kW}$, 并满足 $800 \mathrm{~km}$ 的续航 ${ }^{[4,5]}$. 到目前为止,

引用格式: 任子文, 谭泽昊, 向思否, 等. 基于MOFs材料的非贵金属氧还原电催化剂研究进展. 中国科学: 技术科学, 2022, 52: 375-388 Ren Z W, Tan Z H, Xiang S L, et al. Progress in non-noble metal oxygen reduction electrocatalysts based on MOFs (in Chinese). Sci Sin Tech, 2022, 52: 375-388, doi: 10.1360/SST-2021-0162 
燃料电池汽车在效率、比功率、低温启动、寿命等方 面均已满足大规模产业化的要求，然而其成本还需进 一步大幅降低. 美国能源部(DOE)制定的2050年车用 燃料电池最终商业化成本目标为 30 美元/千瓦, 2020 年 成本评估仍高于其制定的 40 美元/千瓦的目标 ${ }^{[6]}$. 值得 注意的是, $\mathrm{Pt}$ 催化剂的成本约占整个燃料电池电堆成 本的 $41 \%$, 因此, 降低燃料电池Pt用量是实现燃料电池 成本大幅降低的关键.

PEMFC的工作原理如图1所示. 总的电极反应 如下.

阳极发生氧化反应:

$\mathrm{H}_{2} \rightarrow 2 \mathrm{H}^{+}+2 \mathrm{e}^{-}$

阴极发生还原反应:

$\mathrm{O}_{2}+4 \mathrm{H}^{+}+4 \mathrm{e}^{-} \rightarrow 2 \mathrm{H}_{2} \mathrm{O}$

总反应:

$2 \mathrm{H}_{2}+\mathrm{O}_{2} \rightarrow 2 \mathrm{H}_{2} \mathrm{O}$

对于这两种反应，酸性介质中最好的催化剂均为 Pt基催化剂. 阳极的氢氧化反应(HOR)是迄今已知最 快的电化学反应之一，其反应速率比在Pt表面发生的 阴极氧还原反应 $(\mathrm{ORR})$ 要高 $4 \sim 5$ 个数量级 ${ }^{[7]}$, 因此降低 PEMFC中Pt用量主要是指降低阴极的Pt用量. 一方面, 人们不断通过合金化或者超低Pt设计提高比表面活性 和比表面积从而持续降低 $\mathrm{Pt}$ 用量; 另一方面, 开发设计 低成本、高活性、高稳定性非贵金属催化剂被认为是 终极的解决方案. 在过去的几十年, 研究者一直致力于

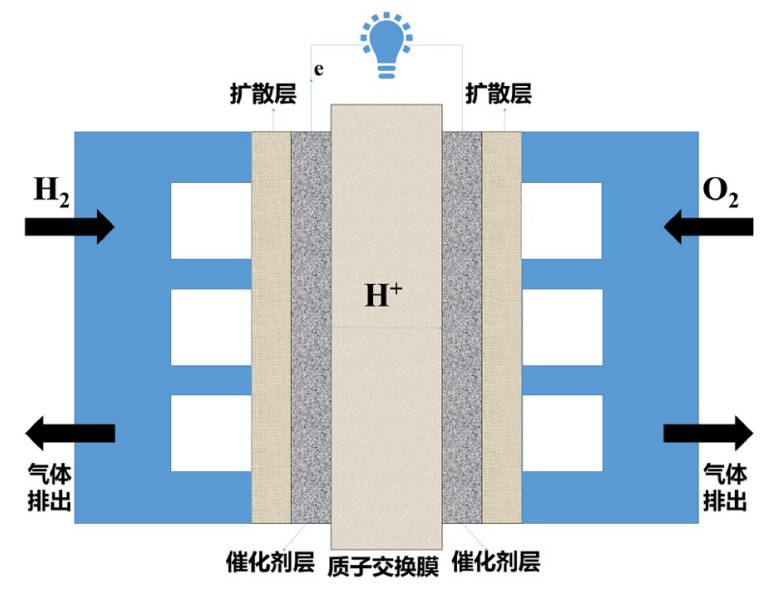

图 1 (网络版彩图) PEMFC结构及工作原理 ${ }^{[1]}$

Figure 1 (Color online) The structure and working principle of PEMFC [1].
寻找可替代Pt的非贵金属ORR电催化剂. 非贵金属 ORR电催化剂主要包括过渡金属氮化物、过渡金属 碳化物、过渡金属-氮-碳(M-N-C)、金属有机框架 (metal-organic frameworks, MOFs)化合物等, 它们根据 前驱体和结构的不同呈现出了不同的性能. 其中, 尤其 以M-N-C这一类催化剂最受关注. 自 1964年酞菁钴 ${ }^{[8]}$ 被发现具有ORR电催化活性以来，过渡金属大环化合 物便相继被用来作为驱体，包括卟啉、酞菁等材 料 $^{[9,10]}$. 1989年Yeager研究团队 ${ }^{[1]}$ 通过热处理Fe或Co 盐、聚苯胺以及高比表面碳混合物同样得到了性能不 错的M-N-C电催化剂, 可与热处理过渡金属大环化合 物的电催化剂性能相媲美. 此后, 通过采用比较便宜 的碳载体、氮源前驱体和无机金属盐而制备的M-N-C 催化剂引起了研究界的重视. 碳源中包括商业碳 球 $^{[12]}$ 、碳纳米管 ${ }^{[13]}$ 、石墨烯 ${ }^{[14]}$ 等; 氮源来源非常广 泛，包括聚苯胺 ${ }^{[15]}$ 、氨气 $气^{[16]}$ 、氨基酸 ${ }^{[17]}$, 也包括天然 含氮物质 ${ }^{[18]}$ 和小分子含氮化合物 ${ }^{[19]}$ 等; 金属源的选择 则主要为 $\mathrm{Fe}, \mathrm{Co}, \mathrm{Mn}, \mathrm{Ni}$ 等 ${ }^{[20]}$. 由于 $\mathrm{M}-\mathrm{N}-\mathrm{C}$ 电催化剂 的制备过程需要高温热处理, 目前得到的催化剂容易 团聚、烧结，活性和稳定性同商业 $\mathrm{Pt} / \mathrm{C}$ 尚有较大差距， 同时过于复杂的催化剂设计和制备大大限制了 M-N-C 电催化剂的产业化应用, 需要寻找更合适的各种前 驱体.

\section{MOFs材料研究的发展和现状}

MOFs材料具有高比表面积、高孔隙率、高可修 饰等有利于反应活性构建的结构特点, 研究者们也已 对MOFs材料的各项应用进行了广泛研究, 得到了一 些结论. MOFs是一种由无机金属和有机配体以配位 键的形式连接而形成的具有分子孔隙的三维网状纳米 粒子, 诞生于1995年, Yaghi研究团队 ${ }^{[21]}$ 通过合成均苯 三甲酸(BTC)与Co而得到了一种二维配位化合物，并 取名为MOFs. 该团队 ${ }^{[22]}$ 在此基础上采用苯二甲酸 (BDC)与 Zn构筑了一种具有永久孔洞的三维金属有机 骨架材料, 并取名为MOF-5. 该材料具有简单立方结 构，立方体八个顶点(金属节点)通过含有苯环的有机 分子连接，每个金属节点中有四个Zn原子，且被碳原 子、氧原子固定. 该材料因其特有的骨架结构和稳定 性被广泛报道, 被称为MOFs发展历史的一个里程碑. 之后, 各种不同类型的MOFs 被合成 ${ }^{[23,24]}$, 丰富了 
MOFs 家族的种类. Férey研究团队 ${ }^{[25,26]}$ 采用均苯三甲 酸与 $\mathrm{Cr}$ 构筑了一种具有两种介孔笼的超大型分子篮拓 扑结构, 并取名为MIL-100.

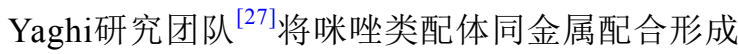
了12种配合物, 并命名为ZIFs(zeolitic imidazolate frameworks). ZIFs 是一种由四面体配位构型的金属离子 和咪唑基有机配体连接而成的具有特定分子结构的三 维骨架, 其架构不仅与沸石的拓扑结构类似, 且金属咪 唑键角也同沸石材料中的硅氧键角接近 ${ }^{[28]}$. 随后该研 究团队 ${ }^{[29 ~ 31]}$ 陆续合成了各类ZIFs材料.

与传统多孔材料相比，具有分子空隙的MOFs材 料结构独特，其特点包括：（1）结构功能的多样性. MOFs材料由各种不同的金属离子和有机配体配位而 成, 且配位模式各异, 在实际应用中, 可根据不同使用 条件和需求调节配体材料或长度，制备不同结构的 MOFs材料, 达到特定的性能要求. (2) 超高的比表面 积. 高比表面积是催化、吸附等应用的重要衡量指标 之一, MOFs的骨架结构会使其普遍具有超高的比表 面积, 如MOF- $5^{[22]}$ 的比表面积高达 $3000 \mathrm{~m}^{2} / \mathrm{g}$, 而Yaghi 研究团队 ${ }^{[32]}$ 合成的MOF-210比表面积可达 $6240 \mathrm{~m}^{2} / \mathrm{g}$. （3）优异的可修饰性. MOFs材料特有的孔洞结构具有 高密度的空隙, 热处理后可以通过其有机配体官能团
或不饱和的金属簇作为位点，通过修饰得到新的功能 特性.

MOFs自合成以来被广泛应用于各类研究领域 ${ }^{[33]}$ (如图 $2^{[34-39]}$ 所示), 包括: (1) 质子传导. MOFs材料可构 建氢键网络, 获得更高的质子传导率. Yaghi研究团 队 ${ }^{[34]}$ 在室温和 $98 \%$ 相对湿度条件下, 合成了一种新的 三维Fe-CAT- 5 材料, 质子传导率达 $0.05 \mathrm{~S} / \mathrm{cm}$. (2) 药物 运输. 因其高比表面积和孔隙率, MOFs材料也常被应 用于药物运输领域. Rosi研究团队 ${ }^{[35]}$ 采用bio-MOF-1材 料实现了抗心律失常药物的存储与运输. (3) 生物医学 成像. 因具有可控的孔径及良好的生物兼容性, MOFs 常被用于生物医学领域. Lin研究团队 ${ }^{[36]}$ 使用 Gd-MOF 材料作为造影剂, 因其高电子弛豫率, 得到了较好的磁 共振成像效果, 开启了MOFs材料在生物医学成像领 域的应用. (4) 气体的吸附、存储与分离. MOFs材料 由于其高比表面积和孔隙率被广泛应用于气体吸附、 存储和分离领域中, 有助于帮助解决日益严重的环境 污染等问题. Yang研究团队 ${ }^{[40]}$ 制备了Zn-MOF薄膜, 实 现了氢气和二氧化碳分子的笁分. Chen研究团队 ${ }^{[37]}$ 在 常温常压下通过MAF-49成功分离乙烯和乙烷. Zhang 研究团队 ${ }^{[41]}$ 使用MAF-23成功纯化1,3-丁二烯, 大幅降 低了原有分离所需的消耗. (5) 苂光传感. 近些年来, 基

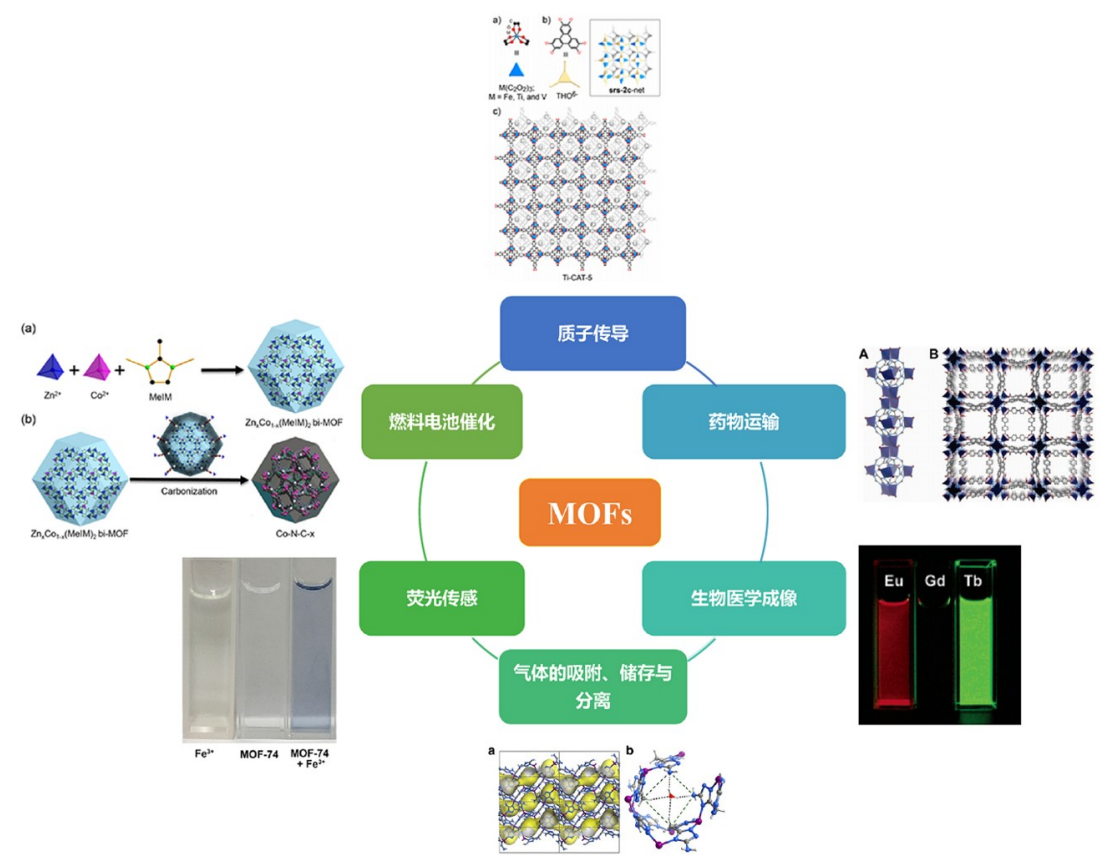

图 2 (网络版彩图) MOFs材料的应用 ${ }^{[34 ~ 39]}$

Figure 2 (Color online) Application of MOFs [34-39]. 
于MOFs材料的荧光传感引起了广泛关注. MOFs的发 光特性同其本身结构、客体物质的相互作用以及孔隙 性质有关. 通过荧光传感得到的MOFs材料在检测小 分子 ${ }^{[42]}$ 、金属离子 ${ }^{[38,43]}$ 、阴离子 ${ }^{[4,45]}$ 等多个方面都有 着很重要的应用.

除此之外，MOFs材料特别是ZIFs材料，近十几年 在燃料电池电催化剂领域中得到了广泛的研究与发 展. MOFs的结构特点与高性能电催化剂结构设计非 常契合，包括：(1) MOFs 具有高密度、均匀分散的活 性中心; (2) 多孔结构, 有利于活性位点暴露, 同时也有 利于物质传输; (3) 孔结构固定, 有利于保障循环的稳 定性; (4) 合成方法多样, 可根据实际催化条件的需求 选取不同的金属和有机配体合成不同的催化剂，为异 质原子的均匀掺杂创造了条件，并根据不同的反应条 件得到孔径不同、结构各异的催化剂; (5) 高温下热 稳定性保障了催化剂在热解过程中不会分解；(6) 超 高比表面积，有效提升了反应速率．因此，基于MOFs 材料的M-N-C燃料电池ORR电催化剂逐渐成为非贵金 属催化领域的研究热点.

\section{3 基于MOFs材料的M-N-C 电催化剂}

如图 $3^{[46-50]}$ 所示, MOFs 材料可通过不同方式用于 制备非贵金属ORR电催化剂. 基于MOFs材料三维结 构、高稳定性、可修饰性等优异特性，直接进行高温 处理即可获得ORR性能优越的电催化剂.

\section{1 基于MOFs的过渡金属基催化剂}

\subsection{1 基于 MOFs的铁基催化剂}

Fe-N-C电催化剂被普遍认为是M-N-C系列催化剂 中活性最高的. Liu研究团队 ${ }^{[46]}$ 将Fe引入ZIF-8 中, 通过 烧结等得到的 $\mathrm{Fe}-\mathrm{N}-\mathrm{C}$ 催化剂在酸性条件下半波电位 达到 0.755 V. Hong研究团队 ${ }^{[51]}$ 采用沸石型纳米级金属 有机骨架来合成氮掺杂的石墨多孔碳，其在碳化过程 中可同时作为碳源和氮源. 烧结后不仅保留了模板的 纳米多面体形态，同时也具有高表面积、良好的导电 性和丰富的氮含量，实验测得其在碱性条件下与商业 $\mathrm{Pt} / \mathrm{C}$ 相比具有相当的性能和四电子转移过程, 电子转 移数高达 3.9 , 且有着优异的甲醇耐受性和循环稳定 性. Kaliaguine研究团队 ${ }^{[52]}$ 合成了含Fe的金属有机骨 架, 并在 $\mathrm{Ar}$ 气氛下进行热解、酸洗, 随后在 $\mathrm{NH}_{3}$ 条件下 于不同温度条件进行热处理, 得到的催化剂于 $950^{\circ} \mathrm{C}$ 下活性最佳，其半波电位能达到 $0.811 \mathrm{~V}$. Wu研究团 队 ${ }^{[53]}$ 打造了一种无氧环境并引入了表面活性剂使溶 液体系的界面状态发生变化以控制生成的颗粒大小, 并有效地促进了碱性锌盐的形成，其电化学反应半波 电位高达 $0.82 \mathrm{~V}$. Li 研究团队 ${ }^{[54]}$ 开发了一种简易方法 来制备具有高活性和耐久性的非贵金属电催化剂，通 过在ZIF-8框架中使用血红素客体在空间上分离 $\mathrm{Fe}^{2+}$ 和 烃支链以形成丰富的Fe- $\mathrm{N}_{x}$ 活性位，而锌的蒸发形成了 多孔的结构. 得到的催化剂在碱性条件下半波电位达 到 $0.86 \mathrm{~V}$ ，酸性条件下达到 $0.81 \mathrm{~V}$, 并具有出色的耐久 性和良好的甲醇耐受性. Wu研究团队 ${ }^{[47]}$ 将 $\mathrm{Fe}$ 离子直接
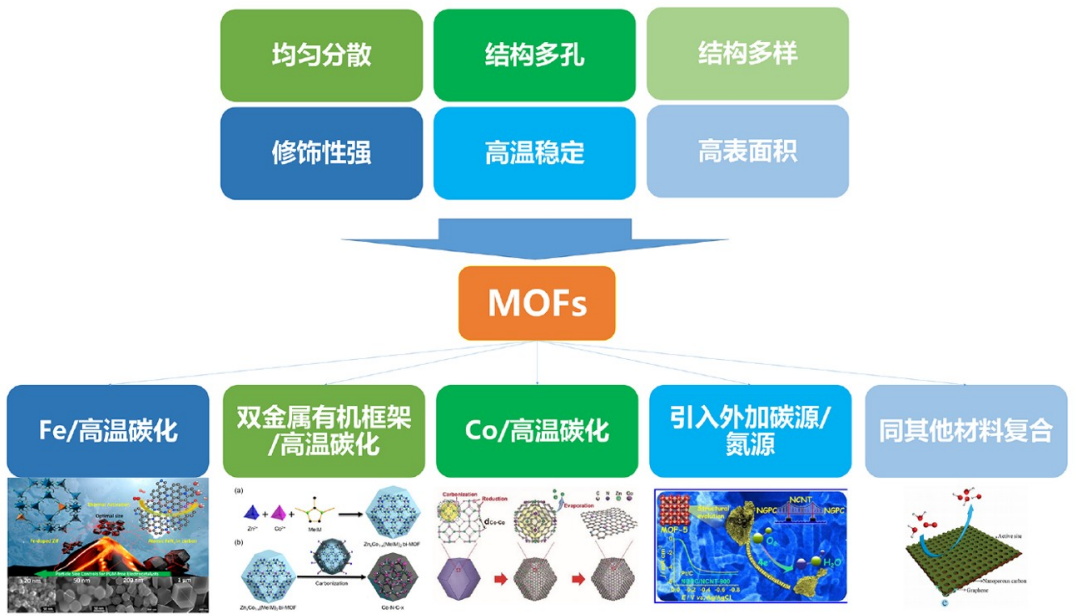

图 3 (网络版彩图)基于MOFs材料的非贵金属电催化剂 ${ }^{[46-50]}$

Figure 3 (Color online) Non-precious metal electrocatalysts based on MOFs [46-50]. 
键合到3D骨架内的咪唑配体(ZIF-8)上，通过精准调节 反应溶剂比例而得到20 1000 nm不同尺寸的催化剂 颗粒。如图4所示，该催化剂在尺寸为 $50 \mathrm{~nm}$ 时性能最
佳，且在酸性条件下半波电位高达 $0.85 \mathrm{~V}(0.5 \mathrm{~mol} / \mathrm{L}$ $\left.\mathrm{H}_{2} \mathrm{SO}_{4}\right)$, 并具有较高的稳定性. 此制备方法简易便捷, 无需酸浸、二次热处理等多余步骤，有大规模生产的

(a)
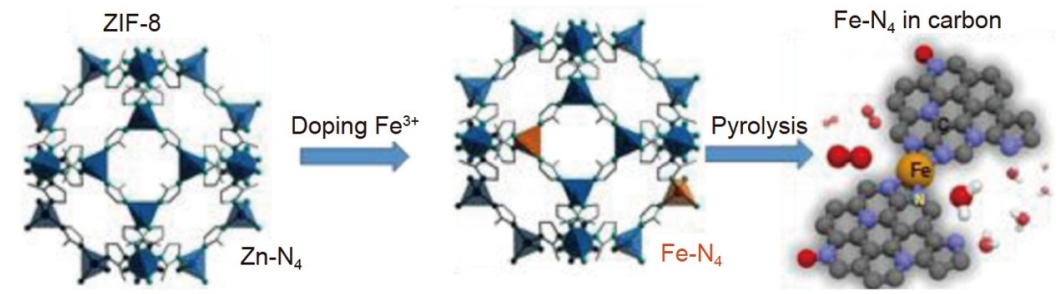

(b) (i)
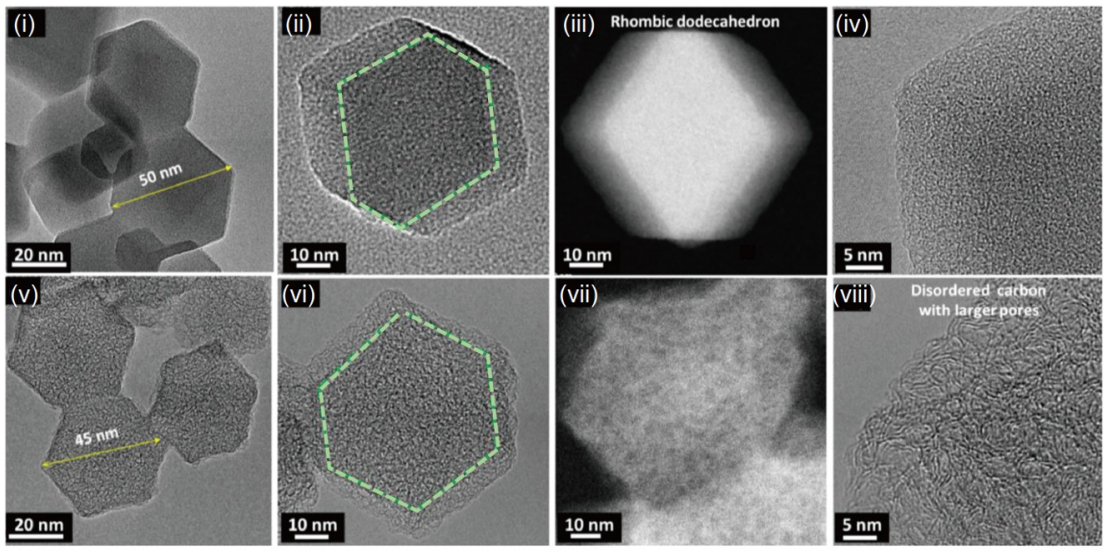

(c)
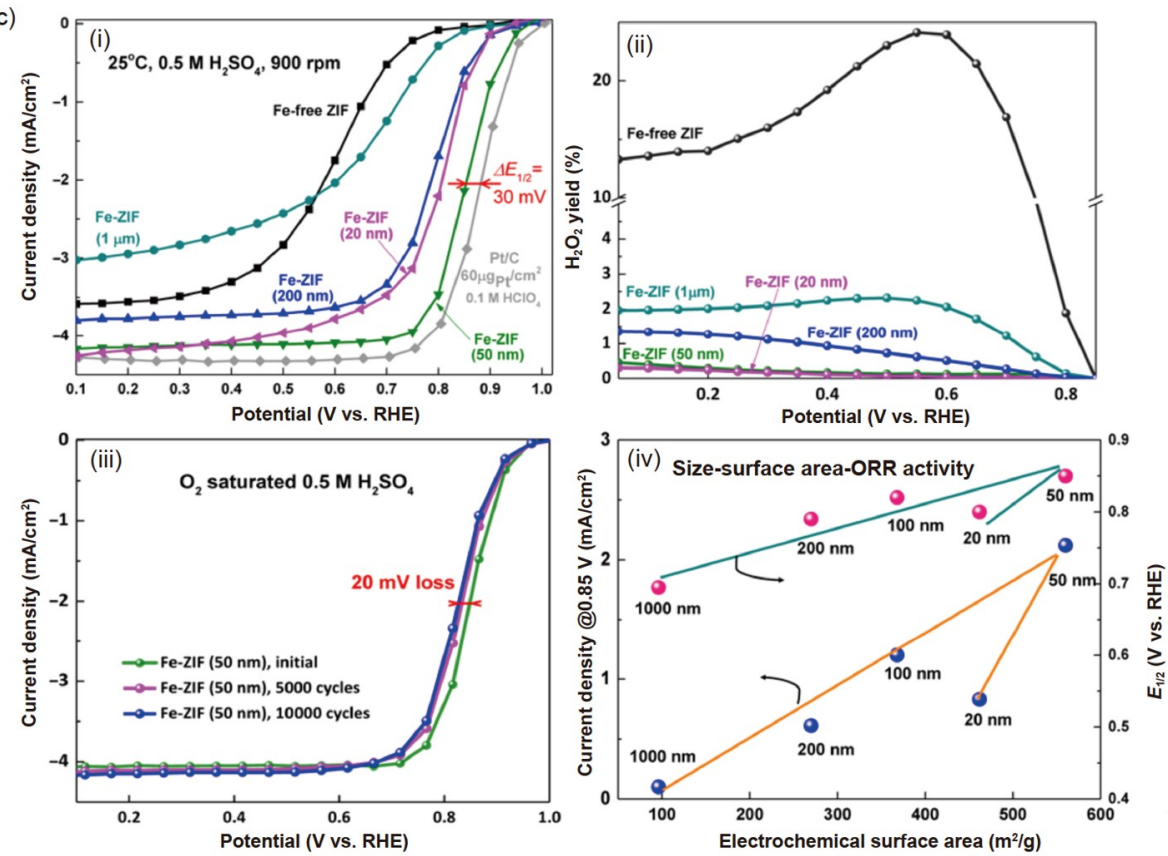

图 4 (网络版彩图) (a) 合成原理. (b) ZIF前驱体与相应催化剂之间的形貌和微观结构. (c) 电化学性能曲线: (i) ORR极化曲线; (ii) $\mathrm{H}_{2} \mathrm{O}_{2}$ 效率; (iii) 稳定性; (iv) ORR活性同颗粒尺寸之间的关系 ${ }^{[4]}$

Figure 4 (Color online) (a) Synthesis principles of Fe-doped ZIF-derived catalysts. (b) Morphology and microstructure between Fe-doped ZIF nanocrystal precursors and the corresponding catalysts. (c) Electrochemical performance plots: (i) ORR polarization plots; (ii) calculated $\mathrm{H}_{2} \mathrm{O}_{2}$ yield; (iii) stability AST; (iv) correlation between ORR activity and surface area (Sa) indicating a clear size dependence [47]. 
可能. 催化剂颗粒大小对于反应活性的影响很大. 较大 的催化剂颗粒将使得比表面积较低, 降低反应活性; 而 颗粒过小同样会导致颗粒团聚现象的产生.

\subsection{2 基于 MOFs的其他金属基催化剂}

由于 Fe本身含有芬顿反应 ${ }^{[55]}$, 在酸性条件下反应 过程中会发生膜中毒和催化剂变性，从而导致含 $\mathrm{Fe}$ 的 MOFs材料催化剂的稳定性不佳, 因此, 研究者们在非 铁 $\mathrm{Fe}$ 领域寻求性能较佳的催化剂. 相较于其他金属, 含 Co的性能较好, 且芬顿反应较弱. Wang研究团队 ${ }^{[48]}$ 采 用直接热解的方法, 以ZIF-67为原料合成含氮的催化 材料. Yang研究团队 ${ }^{[56]}$ 以ZIF-67为前驱体成功合成了 具有多面体形态和多孔结构的含 Co催化剂, 该催化剂 同时掺杂了 $\mathrm{Ni}$ 和P, 两种元素的掺杂对催化剂的结构和 性能有很大的影响. 实验测得其在碱性条件下有较好 的活性, 同商业 $\mathrm{Pt} / \mathrm{C}$ 接近. 然而, 由于Co在酸性条件下 性能一般不高, 早期的研究主要停留在碱性条件下, 对 于催化剂的反应条件有较大限制. Wu研究团队 ${ }^{[57]}$ 通过 一步热活化从掺 Co 的MOFs材料中衍生出高性能的氮 配位的单个Co原子催化剂. 通过研究Co掺杂含量和热 活化温度的影响, 得到在酸性介质中有较好性能和稳 定性的单原子催化剂, 其半波电位达到 $0.80 \mathrm{~V}$, 同时进 行了单电池测试. 经分析认为, ORR性能的显著提高归 因于嵌入在 $3 \mathrm{D}$ 多孔MOFs 衍生且分散良好的 $\mathrm{CoN}_{4}$ 活性 位点的存在. 该研究团队继续研究Co掺杂催化剂 ${ }^{[58,59]}$, 不仅详细地阐释了 $\mathrm{Co}$ 作为金属元素参与反应中的特 点和优势，同时也对反应中可能出现的芬顿反应的抑 制作了思考. 文章指出, Co 在催化剂中的活性位点不 一定是 $\mathrm{CoN}_{4}$, 也可能是 $\mathrm{Co}_{2} \mathrm{~N}_{5}$, 同时反应温度、掺杂 量、颗粒大小等各个方面都会对催化剂的稳定性有着 很大的影响. 该研究团队同时还设计了通过表面活性 剂辅助的有机框架, 其与ZIF-8纳米晶体之间的内聚相 互作用结合成了一种独特的封闭效应，抑制了 Co 原子 位的团聚并减轻了ZIF-8内部微孔结构的破坏. 经过理 论计算，这种新型原子分散的催化剂被认为包含有大 量的 $\mathrm{Co}_{2+2}$ 位点, 在四电子 $\mathrm{ORR}$ 路径中具有活性和热力 学的巨大优势.

除 $\mathrm{Co}$ 外, $\mathrm{Mn}, \mathrm{Ni}$ 等金属元素也被研究用来制备催 化剂. 然而由于其活性不如 $\mathrm{Fe}, \mathrm{Co}$, 目前主要用来作为 双金属催化剂的掺杂元素, 单元素的较少. Wang和 Wu 研究团队 ${ }^{[39]}$ 制备了一种由原子分散在部分石墨碳上
的氮配位的 $\mathrm{Mn}$ 基催化剂，得到的半波电位达 $0.80 \mathrm{~V}$, 且在酸性介质中的稳定性较相同条件下的 $\mathrm{Fe}$ 基催化剂 更强，并通过第一性原理证明了 $\mathrm{MnN}_{4}$ 为其活性位点. 然而比较来看, 其活性与 $\mathrm{Fe}$ 和 $\mathrm{Co}$ 仍尚有一定差距.

\subsection{3 基于MOFs的双金属催化剂}

由于MOFs材料本身即含有金属离子, 离子间不同 性能和相互作用也会对催化剂的性质有着较大影响. 通过不断尝试, 研究者们通过合成双金属有机框架(bi$\mathrm{MOFs}$ )得到性能更佳的催化剂. Sun研究团队 ${ }^{[60]}$ 合成了 一种双金属有机框架, 反应初期 $\mathrm{Zn}$ 的存在使得 $\mathrm{Co}$ 在空 间上彼此隔离, 从而抑制了其在热解过程中的烧结. 而 $\mathrm{Zn}$ 在高温热处理过程中蒸发, 提高了所得催化剂的比 表面积, 催化剂本身的形态、结构和性能亦可根据 $\mathrm{Zn} / \mathrm{Co}$ 的比例而调整. 得到的催化剂在碱性条件下半 波电位达 $0.87 \mathrm{~V}$, 具有较强的稳定性和甲醇耐受性. $\mathrm{Li}$ 研究团队 ${ }^{[61]}$ 采用了类似的方法进行合成, 并在热处理 时采用惰性气氛，得到当MOFs前驱体中 $5 \%$ 的 $\mathrm{Zn}$ 被Co 取代时的性能最好. 制得的催化剂在碱性条件下的半 波电位高达 $0.90 \mathrm{~V}$. Wei研究团队 ${ }^{[62]}$ 同样合成了一种类 似的双金属有机框架, 如图5所示, 但实验测得最佳活 性的 $\mathrm{Zn}$ 和 $\mathrm{Co}$ 的比例与之前不同. 热解过程中 $\mathrm{Zn}$ 的消除 使得催化剂形成了比较强的介孔性，在含有 $22.5 \%$ 的 $\mathrm{Co}$ 时的活性最佳，在碱性条件下的半波电位可高达 $0.91 \mathrm{~V}$, 高于市面上的 $\mathrm{Pt} / \mathrm{C}$ 催化剂. 研究者分析高活性 和高电流密度主要归因于高度分散的 $\mathrm{Co}$ 纳米颗粒和 介孔性质。

此外, 研究者们还通过模板法打造特殊的纳米结 构, 通过结构特性改善催化剂的活性和稳定性. Zhang 研究团队 ${ }^{[63]}$ 设计了一种基于中空多孔的纳米笼双金 属催化剂，该笼具有纳米立方体状金属有机骨架结构, 内含金属 Mn和Co. 采用纳米笼结构使得该催化剂具有 更好的催化活性、更高的稳定性和更宽的工作范围. 中空多孔结构保障了高比表面积和更多的活性位点, 内含的双金属均匀分布和协同效应也同样对活性、稳 定性有促进作用. 该研究再一次验证了中空多孔结构 和良好分散的活性成分对于催化剂性能的积极影响. Zhang研究团队 ${ }^{[49]}$ 引入二氧化硅作为模板, 将Zn-CoZIF合成物质封装在介孔二氧化硅中, 形成了一种碳 的多面体结构, 经过酸浸后得到的催化剂具有很高的 比表面积, 在碱性条件下活性高于商业Pt/C. 不同类型 

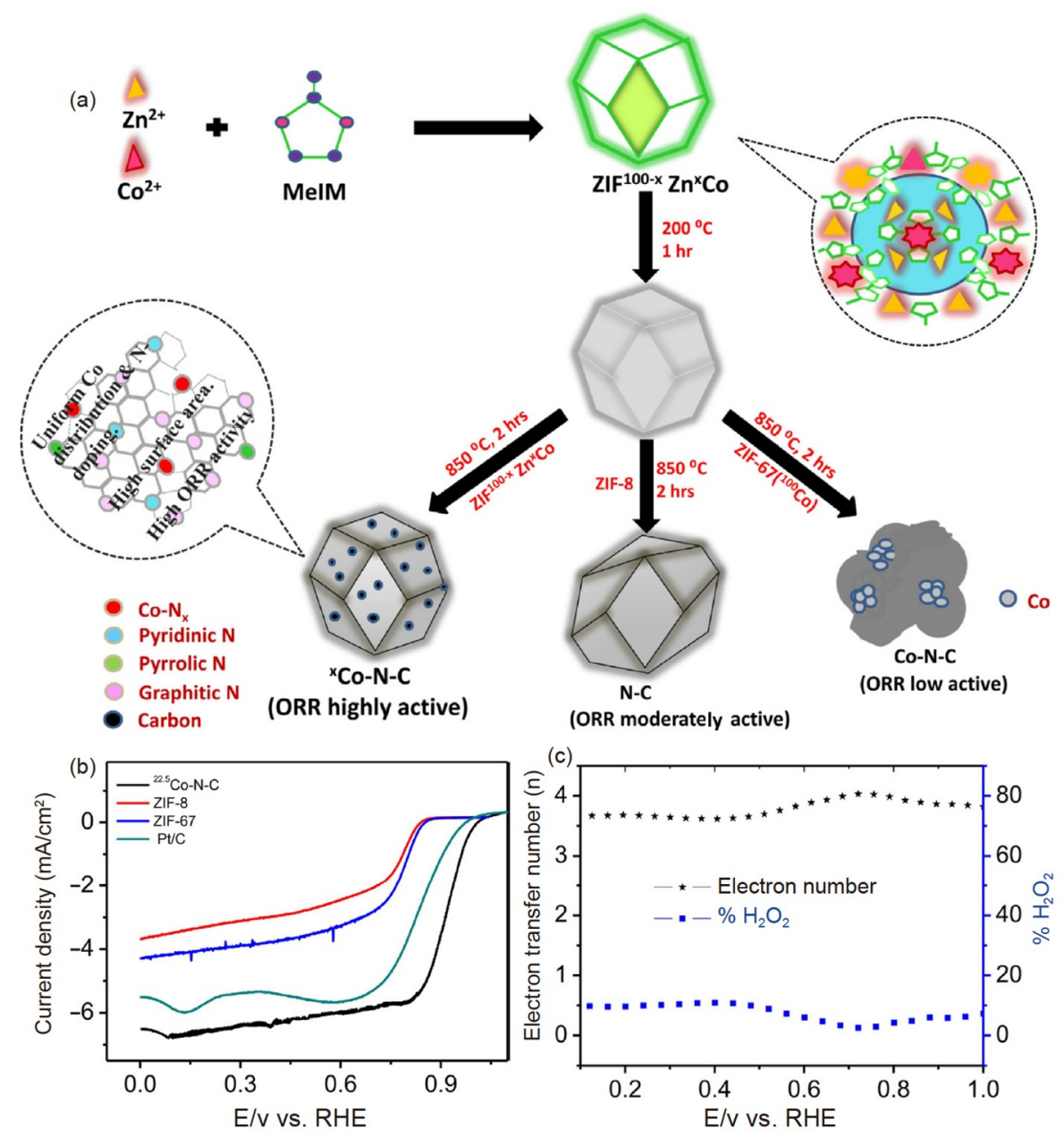

图 5 (网络版彩图) (a) 合成原理; (b) ORR曲线; (c) 电子转移数和双氧水生成率 $(0.1 \mathrm{~mol} / \mathrm{L} \mathrm{KOH})^{[62]}$

Figure 5 (Color online) (a) Synthesis principles of Co-doped ZIF-derived catalysts; (b) ORR performance; (c) electron transfer number and $\mathrm{H}_{2} \mathrm{O}_{2}$ yield $(0.1 \mathrm{~mol} / \mathrm{L} \mathrm{KOH})[62]$.

的结构对反应有不同的影响，通过改变反应物质的结 构也逐渐成为研究者们在MOFs材料领域研究的一个 新方向.

\subsection{4 基于MOFs的特殊结构催化剂}

部分研究者将MOFs材料同其他物质复合, 开发出 了不同的结构，通过交互作用得到了性能较好的催化 材料. Song研究团队 ${ }^{[50]}$ 开发了一种ZIF纳米晶体层的 “三明治”结构，通过均质成核、均匀沉积和受限的成 长过程，制备出了一种ZIF/GO/ZIF的“三明治”结构, 其中超小的ZIF纳米晶体(约为 $20 \mathrm{~nm}$ ) 完全覆盖在 GO 上. ZIF的覆盖可以有效抑制 $G O$ 的团聚, 在碳化和酸蚀 后, 形成了具有高表面积的纳米片. 该催化剂在碱性条
件下半波电位达 $0.80 \mathrm{~V}$. 同年, Zhu研究团队 ${ }^{[64]}$ 合成了 一种在碳纳米管上原位生长的金属有机骨架，石墨碳 上的高比表面积和连续催化层的协同效应提高了电解 过程中的活性位点反应活性. Zhang研究团队 ${ }^{[65]}$ 开发 了一种新型催化剂, 在正常ZIF-8 合成的基础上加入了 $\mathrm{GO}$ 悬浊液, 并在 $920^{\circ} \mathrm{C}$ 下应得到多孔Co-N-C催化剂. 合成时在GO片表面加入了金属离子作为交换剂, 形成 了一种 $3 \mathrm{D}$ 结构, 并在碳化后使得ZIF颗粒变成了具有 高比表面积和纳米孔结构的掺氮碳骨架的功能性碳纳 米管结构. 该催化剂在碱性条件下半波电位达 $0.8 \mathrm{~V}$, 电子传输数为 3.89 , 反应稳定性较好. 研究者认为该高 性能和稳定性主要归因于催化剂的高比表面积和物质 之间的相互作用. Wang研究团队 ${ }^{[66]}$ 开发了一种氯化钠 
辅助剥离方法来合成三维的氮掺杂分层多孔材料，通 过调节氯化钠和ZIF-8的质量比和热解温度有效地控 制了所得碳的形态、石墨化程度和氮类型. 得到的催 化剂在碱性条件下半波电位为 $0.87 \mathrm{~V}$, 单电池性能达 $0.207 \mathrm{~W} / \mathrm{cm}^{2}$.

\section{2 基于MOFs的碳源/氮源催化剂}

除了对MOFs材料本身热解直接得到催化剂以外, 研究者们也通过引入外加碳源或氮源来提升催化剂的 碳含量以及氮含量, 而不引入金属, 来增大催化剂的活 性. Cao研究团队 ${ }^{[67]}$ 成功地使用ZIF-7 作为前驱体, 并使 用葡萄糖作为碳源，成功地制备了纳米级的无金属多 孔碳材料. 如图6所示，催化剂表现出了适当的氮含 量、高比表面积、稳健的孔结构和优异的石墨化程 度. 而添加的碳源葡萄糖不仅对环境友好, 同时可以提 高样品的石墨化程度，并起到了去除残留 $\mathrm{Zn}$ 的作用. 通过实验测得，该催化剂有较好的性能，且计时电流
法测试得到其甲醇耐受性远优于商业 $\mathrm{Pt} / \mathrm{C}$ ，在 $25000 \mathrm{~s}$ 测试中仅损失 0.3 V. Kurungot研究团队 ${ }^{[68]}$ 合成了一种 由三聚氰胺和MOF-5混合为前驱体的催化剂, 该催化 剂 $\mathrm{N}$ 质量百分含量高达 $7.0 \%$ ，且具有高比表面积、高 氧还原活性、强稳定性和高传质效率. 该研究团队发 现，高 $\mathrm{N}$ 含量的物质不仅增强了催化剂本身的 $\mathrm{N}$ 含量, 同时也有助于生成更多的活性位点. 同年，Dai研究团 队 ${ }^{[69,70]}$ 使用类似的方法先后合成了氮硫和氮磷硫掺杂 的多孔碳材料. 他们使用尿素、二甲亚砜和MOF-5作 为前驱体，并研究了氮硫和氮磷硫彼此间的协同效应， 得到了在碱性介质中活性、稳定性较好的催化材料. Wang研究团队 ${ }^{[71]}$ 采用MOF-5 和尿素作为氮碳前驱体 并引入镍，制备了一系列氮掺杂的石墨多孔碳和碳纳 米管作为催化剂. 这些催化剂在碱性介质中表现出了 突出的催化活性、耐久性，并和商业 $\mathrm{Pt} / \mathrm{C}$ 对比具有更 佳的甲醇耐受性. 研究者认为催化剂独特的杂化结 构、富氮掺杂和高比表面积的协同作用促进了催化剂 (a)
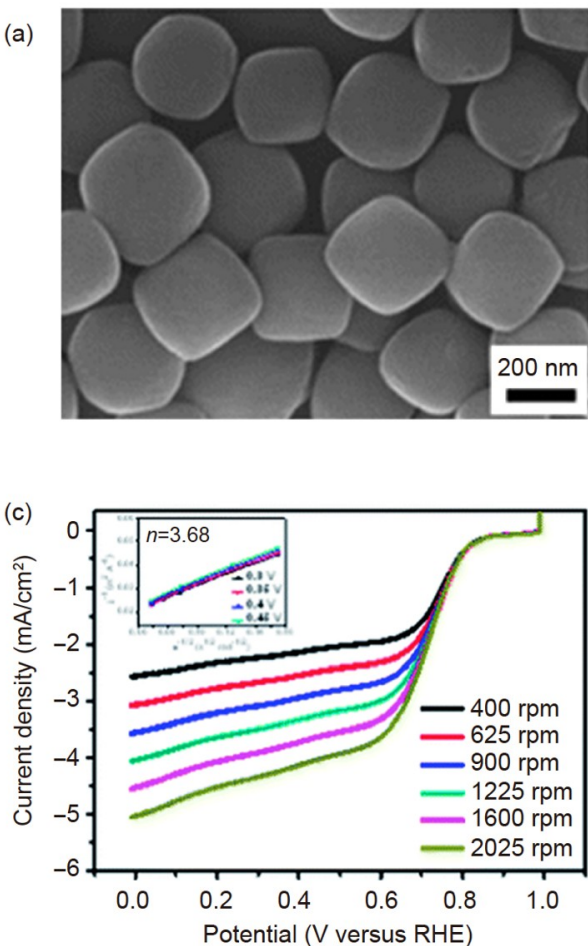
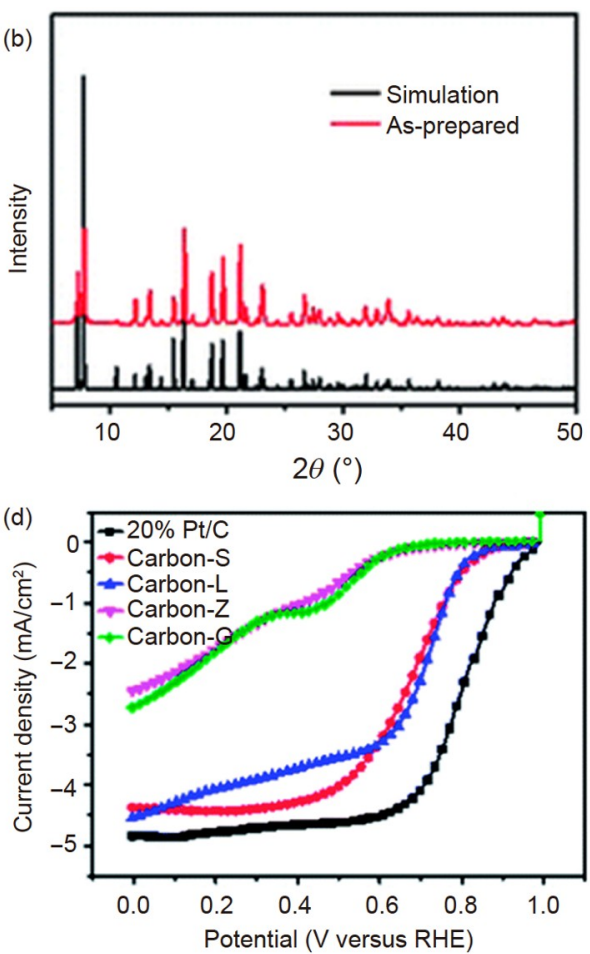

图 6 (网络版彩图) (a) SEM图. (b) XRD图. (c) 在不同旋转圆盘电极转速下的KL图(饱和 $\mathrm{O}_{2}$ 的 $0.1 \mathrm{~mol} / \mathrm{L} \mathrm{KOH}$ 溶液, 扫描速率 为 $5 \mathrm{mV} / \mathrm{s}$, 电子转移数是在 $0.3 \mathrm{~V}$ 电势下计算的). (d) 伏安曲线(饱和 $\mathrm{O}_{2}$ 的 $0.1 \mathrm{~mol} / \mathrm{L} \mathrm{KOH}$ 溶液, 扫描速率为 $5 \mathrm{mV} / \mathrm{s}$, 转速 $1600 \mathrm{r} / \mathrm{min})^{[67]}$

Figure 6 (Color online) (a) SEM image. (b) XRD image. (c) Koutecky-Levich (KL) plots at different rotating disk electrode speeds in $\mathrm{O}_{2}$-saturated $0.1 \mathrm{~mol} / \mathrm{L} \mathrm{KOH}$ with a sweep rate of $5 \mathrm{mV} / \mathrm{s}$. Electron transfer number $(n)$ is calculated at the potential of $0.3 \mathrm{~V}$. (d) Linear-sweep voltammograms in $0.1 \mathrm{~mol} / \mathrm{L} \mathrm{KOH}$ under oxygen bubbling at a scan rate of $5 \mathrm{mV} / \mathrm{s}$ and electrode-rotation speed of $1600 \mathrm{r} / \mathrm{min}$ [67]. 
的氧还原活性.

根据各研究团队对基于MOFs材料的非贵金属氧 还原电催化剂性能研究, 汇总如表1所示.

\section{4 活性机理和膜电极研究}

基于MOFs材料的ORR电催化剂反应机理取决于 金属和前驱体之间的协同效应及其特有的结构特点. 正如前文所介绍的各类催化剂的性能分析，因其金属 和前驱体之间的协同效应而导致了不同的性能. 而催 化剂的大比表面积、介孔微孔性质、高氮含量(以石 墨氮、吡啶氮、吡咯氮为主)、分布均匀的金属颗粒 等, 也均通过多次试验证明对于催化剂的性能和稳定 性有着较大影响.

目前, M-N-C电催化剂在酸性介质中的ORR反应 机制尚不明确, 且其活性位点也没有一个定论 ${ }^{[3]}$. 普遍 认为嵌入碳中的 $M-N_{4}$ 可能是 M-N-C 催化剂在酸性介 质中拥有催化活性的原因之一. Wang研究团队 ${ }^{[72]}$ 通过
DFT实验，预测得到 $\mathrm{Fe}$ 催化剂的 $\mathrm{FeN}_{4}$ 位点主要通过四 电子反应途径进行, 而 $\mathrm{CoN}_{4}$ 位点上 $\mathrm{O}-\mathrm{O}$ 键分裂的高活 化能以及 $\mathrm{H}_{2} \mathrm{O}_{2}$ 的弱吸附性, 会使得 $\mathrm{CoN}_{4}$ 位点以二电子 途径进行. 然而, 二电子反应中会生成很多过氧化氢, 这也同样导致反应的活性及稳定性的降低, 这也是普 遍在酸性条件下 Fe 的活性大于 Co 的活性的主要原因 之一. 该研究团队同时通过实验证明了其理论假设, 认 为 $\mathrm{FeN}_{4}$ 和 $\mathrm{CoN}_{4}$ 是酸性介质中 $\mathrm{M}-\mathrm{N}-\mathrm{C}$ 催化剂 $\mathrm{ORR}$ 上的 主要活性位点. 对于 $\mathrm{Fe}, \mathrm{FeN}_{4}$ 往往被认为是在酸性条件 下的主要活性位点. 然而, 由于 $\mathrm{Fe}$ 在酸性条件下极易产 生芬顿反应 ${ }^{[5]}$, 研究者们也试图通过采用合理的方法 减少过氧化氢或相关官能团的产生，以抑制过氧化氢 的影响.

同Fe相比，Co由于其反应时主要以二电子途径进 行, 因此在早年酸性条件下的研究不多. 然而, 近年研 究者们通过实验发现Co也可以通过四电子路径参与 反应. Wu研究团队 ${ }^{[57]}$ 也通过很多的表征手法证明了 $\mathrm{CoN}_{4}$ 活性位点的存在, 但提出了某些活性位点不一定

表 1 基于MOFs材料的非贵金属氧还原电催化剂性能

Table 1 Performance of non-noble metal oxygen reduction electrocatalysts based on MOFs

\begin{tabular}{|c|c|c|c|c|c|c|}
\hline MOFs前驱体 & 衍生材料 & 制备方法 & 半波电位 (V) & 电解液 & 单电池功率密度 $\left(\mathrm{W} / \mathrm{cm}^{2}\right)$ & 参考文献 \\
\hline ZIF-8 & $\mathrm{Fe}-\mathrm{N}-\mathrm{C}$ & 热处理, 酸洗 & 0.755 & $0.1 \mathrm{~mol} / \mathrm{L} \mathrm{HClO}_{4}$ & 0.287 & [46] \\
\hline ZIF-8 & N-PC & 热处理, 酸洗 & -0.198 (vs. $\mathrm{Ag} / \mathrm{AgCl})$ & $0.1 \mathrm{~mol} / \mathrm{L} \mathrm{KOH}$ & - & [51] \\
\hline Fe-based MOF & $\mathrm{Fe}-\mathrm{N}-\mathrm{C}$ & 热处理, 酸洗, 二次热处理 & 0.811 & $0.1 \mathrm{~mol} / \mathrm{L} \mathrm{H}_{2} \mathrm{SO}_{4}$ & 0.302 & {$[52]$} \\
\hline ZIF-8 & $\mathrm{Fe}-\mathrm{N}-\mathrm{C}$ & 介导生长, 热处理 & 0.82 & $0.1 \mathrm{~mol} / \mathrm{L} \mathrm{HClO}_{4}$ & - & [53] \\
\hline ZIF-8 & $\mathrm{Fe}-\mathrm{N}-\mathrm{C}$ & 热处理 & 0.9 & $0.1 \mathrm{~mol} / \mathrm{L} \mathrm{KOH}$ & - & [54] \\
\hline ZIF-8 & Fe-N-C & 热处理 & 0.85 & $0.5 \mathrm{~mol} / \mathrm{L} \mathrm{H}_{2} \mathrm{SO}_{4}$ & - & [47] \\
\hline ZIF-8/ZIF-67 & Co-N-C & 热处理 & 0.8 & $0.5 \mathrm{~mol} / \mathrm{L} \mathrm{H}_{2} \mathrm{SO}_{4}$ & 0.56 & {$[57]$} \\
\hline $\mathrm{Co} / \mathrm{ZIF}-8$ & Co-N-C & 介导生长, 热处理 & 0.84 & $0.5 \mathrm{~mol} / \mathrm{L} \mathrm{H}_{2} \mathrm{SO}_{4}$ & 0.87 & [59] \\
\hline ZIF-8/ZIF-67 & Co-N-C & 热处理 & 0.871 & $0.1 \mathrm{~mol} / \mathrm{L} \mathrm{KOH}$ & - & [39] \\
\hline ZIF-8/ZIF-67 & Co-N-C & 热处理 & 0.9 & $0.1 \mathrm{~mol} / \mathrm{L} \mathrm{KOH}$ & - & {$[60]$} \\
\hline ZIF-8/ZIF-67 & Co-N-C & 热处理 & 0.91 & $0.1 \mathrm{~mol} / \mathrm{L} \mathrm{KOH}$ & - & [61] \\
\hline $\mathrm{Co} / \mathrm{ZIF}-8$ & Co-N-C & 热处理, 酸浸 & $-0.175($ vs. $\mathrm{Ag} / \mathrm{AgCl})$ & $0.1 \mathrm{~mol} / \mathrm{L} \mathrm{KOH}$ & - & [63] \\
\hline ZIF-7 & N-PC & 热处理 & 0.7 & $0.1 \mathrm{~mol} / \mathrm{L} \mathrm{KOH}$ & - & [49] \\
\hline ZIF-8 & CNT & 热处理 & 0.887 & $0.1 \mathrm{~mol} / \mathrm{L} \mathrm{KOH}$ & - & {$[50]$} \\
\hline ZIF-8 & NHPC & 沉淀, 热处理 & 0.87 & $0.1 \mathrm{~mol} / \mathrm{L} \mathrm{KOH}$ & 0.207 & {$[65]$} \\
\hline MOF-5 & $\mathrm{g}-\mathrm{C} 3 \mathrm{~N} 4$ & 热处理 & 0.035 (vs. $\mathrm{Hg} / \mathrm{HgO}$ ) & $0.1 \mathrm{~mol} / \mathrm{L} \mathrm{KOH}$ & - & {$[67]$} \\
\hline MOF-5 & NS-C & 热处理, 酸洗 & -0.135 (vs. $\mathrm{Ag} / \mathrm{AgCl})$ & $0.1 \mathrm{~mol} / \mathrm{L} \mathrm{KOH}$ & - & {$[68]$} \\
\hline MOF-5 & NGPC/NCNT & 热处理, 酸洗, 二次热处理 & -0.161 (vs. $\mathrm{Ag} / \mathrm{AgCl})$ & $0.1 \mathrm{~mol} / \mathrm{L} \mathrm{KOH}$ & - & {$[70]$} \\
\hline ZIF-8 & Co-N-C & 原位生长, 热处理 & 0.82 & $0.1 \mathrm{~mol} / \mathrm{L} \mathrm{KOH}$ & - & [71] \\
\hline
\end{tabular}


是 $\mathrm{CoN}_{4}$ 的可能. 该研究团队 ${ }^{[59]}$ 通过使用 HAADF, STEM和EELS 首次观测到了 $\mathrm{Co}-\mathrm{N}-\mathrm{C}$ 催化剂中 $\mathrm{Co}$ 和 N 原子之间的配位, 并建模计算得出 $\mathrm{CoN}_{4}$ 和 $\mathrm{Co}_{2+2}$ 两种位 点参与 ORR反应的路径不同. 其结果得到 $\mathrm{Co}_{2+2}$ 可以通 过类似于 $\mathrm{FeN}_{4}$ 的四电子进行反应，但 $\mathrm{CoN}_{4}$ 只能通过二 电子进行反应. 该研究同前文相比提出了 $\mathrm{Co}_{2+2}$ 这种新 的配位形式. 该研究团队同年 ${ }^{[58]}$ 还提出了另一种 $\mathrm{Co}_{2} \mathrm{~N}_{5}$ 的配位方式. 综上, 对于Co而言, 确定其活性位 点的配位形式以及二电子、四电子的反应路径仍是研 究者们需要攻克的重点.

然而, 当前的MOFs催化剂性能表征仍停留在旋转 圆盘电极(RDE)测试阶段，虽然目前大部分催化剂在 半波电位指标上已经接近甚至超过商业 $\mathrm{Pt} / \mathrm{C}$ 催化剂, 但在电池测试中的表现却不尽如人意. 由于非贵金属 催化剂的质量比活性较低, 目前需要应用在膜电极上 的催化剂载量更高 ${ }^{[73]}$, 因此其催化剂厚度(约 $\left.100 \mu \mathrm{m}\right)$ 远远大于商业 $\mathrm{Pt} / \mathrm{C}(\text { 约 } 10 \mu \mathrm{m})^{[74]}$. Zhang研究团队 ${ }^{[75]}$ 曾 多角度分析基于MOFs的非贵金属催化剂膜电极的性 能, 发现随着催化剂载量的增加, 催化层内的氧气传 质阻力和质子传输阻力也会相应地提高，因此在制备 膜电极时, 需要寻求催化活性、氧气传输和质子传导 之间的平衡. 此外, 该研究团队还发现, 非Pt膜电极 的衰减迅速，原因来自于催化剂活性降低、氧气传 质和质子传导变缓、催化层内液态水凝结等多方面因 素. 他们制备 ${ }^{[76]}$ 了一种高性能的基于Fe-N-C催化剂的 膜电极, 如图7所示, 在初始峰值功率密度高达 $1.1 \mathrm{~W} / \mathrm{cm}^{2}$, 但在 $20 \mathrm{~h}$ 内衰减达 $52 \%$. 通过实验和DFT结
果证明，主要原因是羟基自由基的侵蚀以及铁离子的 污染.

\section{5 总结与展望}

借助于MOFs的三维结构及高稳定性、可修饰性 等特点, 研究者们大大提升了 M-N-C催化剂的ORR活 性及稳定性，但距离实际应用仍有一定距离，仍亟待 解决相关挑战.

首先，需进一步明确活性机理. MOFs本身的结构 特性被认为是优异的ORR电催化剂前驱体，但其热处 理后的催化活性机理尚未明确. 以Co为例, 在研究的 过程中提出 $\mathrm{CoN}_{4}, \mathrm{CoN}_{2+2}, \mathrm{Co}_{2} \mathrm{~N}_{5}$ 等多种可能的活性位 点存在, 而也有观点认为催化剂的活性位点是金属本 身，氮元素的掺杂只是辅助了金属元素的位点活性， 并未形成明确的结构.

其次, 亟需进一步提升酸性条件下ORR电催化性 能, 尤其是稳定性. 值得注意的是, 由于酸性条件下的 强氧化性, $\mathrm{Fe}$ 会产生芬顿反应, 稳定性变差. 相比较而 言, $\mathrm{Co}, \mathrm{Mn}$ 等其他金属在实际测试中却又无法达到足 够好的性能, 稳定性也未满足商业标准. 因此, 需要进 一步探究在酸性条件下的ORR反应机制，思考如何避 免或缓解因芬顿反应等对稳定性的影响.

此外，对于非贵金属催化剂在膜电极层面上的研 究而言, 无论是ORR活性、催化剂阻抗性质、氧气传 输性质等全面、定量的研究，还是目前非常严重的衰 减问题的分析和解决, 都有待进一步探究.
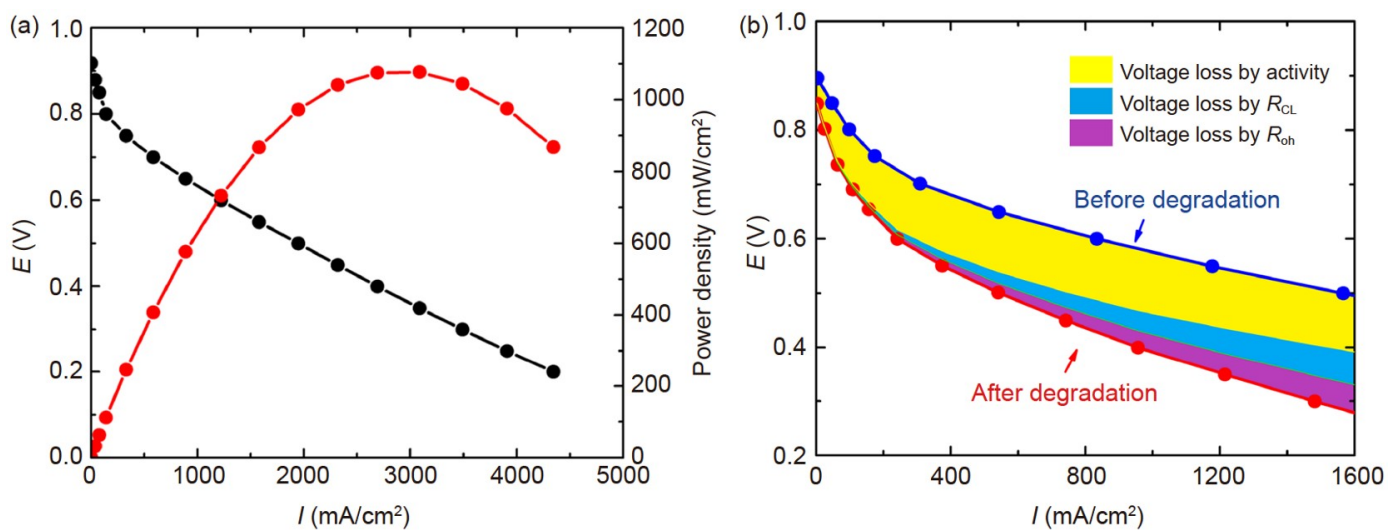

图 7 (网络版彩图) (a) Fe-N-C膜电极初始性能; (b) 降解后的电压损失

Figure 7 (Color online) (a) Initial performance of the Fe-N-C MEA; (b) voltage loss after degradation. 
1 Jacobson M Z. Review of solutions to global warming, air pollution, and energy security. Energy Environ Sci, 2009, 2: 148-173

2 Jaouen F, Proietti E, Lefèvre M, et al. Recent advances in non-precious metal catalysis for oxygen-reduction reaction in polymer electrolyte fuelcells. Energy Environ Sci, 2011, 4: 114-130

3 He Y, Tan Q, Lu L, et al. Metal-nitrogen-carbon catalysts for oxygen reduction in PEM fuel cells: Self-template synthesis approach to enhancing catalytic activity and stability. Electrochem Energ Rev, 2019, 2: 231-251

4 Zhou Y F. Analysis and enlightenment of Japanese fuel cell vehicle strategy (in Chinese). Auto Rev, 2020, 1: 44-45 [周一帆. 日本燃料电池汽车 战略分析及启示. 汽车纵横, 2020, 1: 44-45]

5 Kurokawa Y, Imoto N, Yano K, et al. New energy vehicle market dynamics and technology development trends (in Chinese). Autom New Powertrain, 2020, 3: 21-27 [黒川陽弘, 井本伸, 矢野勝, 等. 新能源汽车市场动态与技术发展趋势. 汽车与新动力, 2020, 3: 21-27]

6 Papageorgopoulos D. Fuel cells R\&D overview. 2019. https://www.hydrogen.energy.gov/

7 Neyerlin K C, Gu W, Jorne J, et al. Determination of catalyst unique parameters for the oxygen reduction reaction in a PEMFC. J Electrochem Soc, 2006, 153: A1955

8 Faubert G, Lalande G, Côté R, et al. Heat-treated iron and cobalt tetraphenylporphyrins adsorbed on carbon black: Physical characterization and catalytic properties of these materials for the reduction of oxygen in polymer electrolyte fuel cells. Electrochim Acta, 1996, 41: 1689-1701

$9 \mathrm{Hu}$ X, Xia D, Zhang L, et al. High crystallinity binuclear iron phthalocyanine catalyst with enhanced performance for oxygen reduction reaction. J Power Sources, 2013, 231: 91-96

10 Bezerra C W B, Zhang L, Lee K, et al. A review of Fe-N/C and Co-N/C catalysts for the oxygen reduction reaction. Electrochim Acta, 2008, 53: $4937-4951$

11 Gupta S, Tryk D, Bae I, et al. Heat-treated polyacrylonitrile-based catalysts for oxygen electroreduction. J Appl Electrochem, 1989, 19: 19-27

12 Guo M, Wang L, Gao Y, et al. Trace sulfur promoted Fe, N-codoped carbon black as electrocatalyst for oxygen reduction reaction. Int J Hydrogen Energy, 2019, 44: 3625-3635

13 Chung H T, Won J H, Zelenay P. Active and stable carbon nanotube/nanoparticle composite electrocatalyst for oxygen reduction. Nat Commun, 2013, 4: 1922

14 Lin Z, Waller G H, Liu Y, et al. 3D Nitrogen-doped graphene prepared by pyrolysis of graphene oxide with polypyrrole for electrocatalysis of oxygen reduction reaction. Nano Energy, 2013, 2: 241-248

15 Yin X, Chung H T, Martinez U, et al. PGM-free ORR catalysts designed by templating PANI-type polymers containing functional groups with high affinity to Iron. J Electrochem Soc, 2019, 166: F3240-F3245

16 Lai L, Potts J R, Zhan D, et al. Exploration of the active center structure of nitrogen-doped graphene-based catalysts for oxygen reduction reaction. Energy Environ Sci, 2012, 5: 7936

17 Yan J, Meng H, Xie F, et al. Metal free nitrogen doped hollow mesoporous graphene-analogous spheres as effective electrocatalyst for oxygen reduction reaction. J Power Sources, 2014, 245: 772-778

18 Wang R, Song H, Li H, et al. Mesoporous nitrogen-doped carbon derived from carp with high electrocatalytic performance for oxygen reduction reaction. J Power Sources, 2015, 278: 213-217

19 Liang J, Jiao Y, Jaroniec M, et al. Sulfur and nitrogen dual-doped mesoporous graphene electrocatalyst for oxygen reduction with synergistically enhanced performance. Angew Chem Int Ed, 2012, 51: 11496-11500

$20 \mathrm{Li} \mathrm{L}, \mathrm{Fu} \mathrm{C}$, Shen S, et al. Influence of Fe on electrocatalytic activity of iron-nitrogen-doped carbon materials toward oxygen reduction reaction. Front Energy, 2020, doi: 10.1007/s11708-020-0669-0

21 Yaghi O M, Li G, Li H. Selective binding and removal of guests in a microporous metal-organic framework. Nature, 1995, 378: 703-706

22 Li H, Eddaoudi M, O'Keeffe M, et al. Design and synthesis of an exceptionally stable and highly porous metal-organic framework. Nature, 1999, 402: $276-279$

23 Chae H K, Siberio-Pérez D Y, Kim J, et al. A route to high surface area, porosity and inclusion of large molecules in crystals. Nature, 2004, 427: 523-527

24 Rosi N L, Kim J, Eddaoudi M, et al. Rod packings and metal-organic frameworks constructed from rod-shaped secondary building units. J Am Chem Soc, 2005, 127: 1504-1518 
25 Férey G, Serre C, Mellot-Draznieks C, et al. A hybrid solid with giant pores prepared by a combination of targeted chemistry, simulation, and powder diffraction. Angew Chem Int Ed, 2004, 43: 6296-6301

26 Férey G, Mellot-Draznieks C, Serre C, et al. A chromium terephthalate-based solid with unusually large pore volumes and surface area. Science, 2005, 309: 2040-2042

27 Park K S, Ni Z, Cote A P, et al. Exceptional chemical and thermal stability of zeolitic imidazolate frameworks. Proc Natl Acad Sci USA, 2006, 103: 10186-10191

28 Venna S R, Jasinski J B, Carreon M A. Structural evolution of zeolitic imidazolate framework-8. J Am Chem Soc, 2010, 132: 18030-18033

29 Hayashi H, Côté A P, Furukawa H, et al. Zeolite A imidazolate frameworks. Nat Mater, 2007, 6: 501-506

30 Banerjee R, Phan A, Wang B, et al. High-throughput synthesis of zeolitic imidazolate frameworks and application to $\mathrm{CO}_{2}$ capture. Science, 2008, 319: 939-943

31 Wang B, Côté A P, Furukawa H, et al. Colossal cages in zeolitic imidazolate frameworks as selective carbon dioxide reservoirs. Nature, 2008, 453: $207-211$

32 Furukawa H, Ko N, Go Y B, et al. Ultrahigh porosity in metal-organic frameworks. Science, 2010, 329: 424-428

33 Xuan C J, Wang J, Zhu J, et al. Recent progress of metal organic frameworks-based nanomaterials for electrocatalysis. Acta Physico-Chim Sin, 2017, 33: 149-164

34 Nguyen N T T, Furukawa H, Gándara F, et al. Three-dimensional metal-catecholate frameworks and their ultrahigh proton conductivity. J Am Chem Soc, 2015, 137: 15394-15397

35 An J, Geib S J, Rosi N L. Cation-triggered drug release from a porous zinc-adeninate metal-organic framework. J Am Chem Soc, 2009, 131: 8376-8377

36 Rieter W J, Taylor K M L, An H, et al. Nanoscale metal-organic frameworks as potential multimodal contrast enhancing agents. J Am Chem Soc, 2006, 128: 9024-9025

37 Liao P Q, Zhang W X, Zhang J P, et al. Efficient purification of ethene by an ethane-trapping metal-organic framework. Nat Commun, 2015, 6: 8697

38 Wang J, Fan Y, Lee H, et al. Ultrasmall metal-organic framework Zn-MOF-74 nanodots: Size-controlled synthesis and application for highly selective colorimetric sensing of iron(III) in aqueous solution. ACS Appl Nano Mater, 2018, 1: 3747-3753

39 Li J, Chen M, Cullen D A, et al. Atomically dispersed manganese catalysts for oxygen reduction in proton-exchange membrane fuel cells. Nat Catal, 2018, 1: 935-945

40 Peng Y, Li Y, Ban Y, et al. Metal-organic framework nanosheets as building blocks for molecular sieving membranes. Science, 2014, 346: 13561359

41 Liao P Q, Huang N Y, Zhang W X, et al. Controlling guest conformation for efficient purification of butadiene. Science, 2017, 356: 1193-1196

42 Chen B, Yang Y, Zapata F, et al. Luminescent open metal sites within a metal-organic framework for sensing small molecules. Adv Mater, 2007, 19: $1693-1696$

43 Peng Y, Huang H, Zhang Y, et al. A versatile MOF-based trap for heavy metal ion capture and dispersion. Nat Commun, 2018, 9: 187

44 Wen $\mathrm{L}$, Zheng $\mathrm{X}, \mathrm{Lv} \mathrm{K}$, et al. Two amino-decorated metal-organic frameworks for highly selective and quantitatively sensing of $\mathrm{Hg}^{\mathrm{II}}$ and $\mathrm{Cr}^{\mathrm{VI}}$ in aqueous solution. Inorg Chem, 2015, 54: 7133-7135

$45 \mathrm{Xu} \mathrm{M} \mathrm{M,} \mathrm{Kong} \mathrm{X} \mathrm{J,} \mathrm{He} \mathrm{T,} \mathrm{et} \mathrm{al.} \mathrm{A} \mathrm{stable} \mathrm{Zr}(\mathrm{IV})$-based metal-organic framework constructed from $\mathrm{C}=\mathrm{C}$ bridged di-isophthalate ligand for sensitive detection of $\mathrm{Cr}_{2} \mathrm{O}_{7}{ }^{2-}$ in water. Inorg Chem, 2018, 57: 14260-14268

46 Zhao D, Shui J L, Chen C, et al. Iron imidazolate framework as precursor for electrocatalysts in polymer electrolyte membrane fuel cells. Chem Sci, 2012, 3: 3200-3205

47 Zhang H, Hwang S, Wang M, et al. Single atomic iron catalysts for oxygen reduction in acidic media: Particle size control and thermal activation. J Am Chem Soc, 2017, 139: 14143-14149

48 Dou S, Li X, Tao L, et al. Cobalt nanoparticle-embedded carbon nanotube/porous carbon hybrid derived from $\mathrm{MOF}^{-e n c a p s u l a t e d ~} \mathrm{Co}_{3} \mathrm{O}_{4}$ for oxygen electrocatalysis. Chem Commun, 2016, 52: 9727-9730

49 Shang L, Yu H, Huang X, et al. Well-dispersed ZIF-derived Co,N-Co-doped carbon nanoframes through mesoporous-silica-protected calcination as efficient oxygen reduction electrocatalysts. Adv Mater, 2016, 28: 1668-1674

50 Wei J, Hu Y, Liang Y, et al. Nitrogen-doped nanoporous carbon/graphene nano-sandwiches: Synthesis and application for efficient oxygen 
reduction. Adv Funct Mater, 2015, 25: 5768-5777

51 Zhang L, Su Z, Jiang F, et al. Highly graphitized nitrogen-doped porous carbon nanopolyhedra derived from ZIF-8 nanocrystals as efficient electrocatalysts for oxygen reduction reactions. Nanoscale, 2014, 6: 6590-6602

52 Afsahi F, Kaliaguine S. Non-precious electrocatalysts synthesized from metal-organic frameworks. J Mater Chem A, 2014, 2: 12270-12279

53 Wang X, Zhang H, Lin H, et al. Directly converting Fe-doped metal-organic frameworks into highly active and stable Fe-N-C catalysts for oxygen reduction in acid. Nano Energy, 2016, 25: 110-119

54 Xue J, Li Y, Hu J. Nanoporous bimetallic Zn/Fe-N-C for efficient oxygen reduction in acidic and alkaline media. J Mater Chem A, 2020, 8: $7145-7157$

55 Kang S F, Chang H M. Coagulation of textile secondary effluents with Fenton's reagent. Water Sci Tech, 1997, 36: 215-222

$56 \mathrm{Li} \mathrm{L}, \mathrm{Xie} \mathrm{W}$, Chen J, et al. ZIF-67 derived P/Ni/Co/NC nanoparticles as highly efficient electrocatalyst for oxygen reduction reaction (ORR). J Solid State Chem, 2018, 264: 1-5

57 Wang X X, Cullen D A, Pan Y T, et al. Nitrogen-coordinated single cobalt atom catalysts for oxygen reduction in proton exchange membrane fuel cells. Adv Mater, 2018, 30: 1706758

58 Wang X X, Prabhakaran V, He Y, et al. Iron-free cathode catalysts for proton-exchange-membrane fuel cells: Cobalt catalysts and the peroxide mitigation approach. Adv Mater, 2019, 31: 1805126

59 He Y, Hwang S, Cullen D A, et al. Highly active atomically dispersed $\mathrm{CoN}_{4}$ fuel cell cathode catalysts derived from surfactant-assisted MOFs: Carbon-shell confinement strategy. Energy Environ Sci, 2019, 12: 250-260

60 You B, Jiang N, Sheng M, et al. Bimetal-organic framework self-adjusted synthesis of support-free nonprecious electrocatalysts for efficient oxygen reduction. ACS Catal, 2015, 5: 7068-7076

61 Wang X, Fan X, Lin H, et al. An efficient Co-N-C oxygen reduction catalyst with highly dispersed Co sites derived from a ZnCo bimetallic zeolitic imidazolate framework. RSC Adv, 2016, 6: 37965-37973

62 Shah S S A, Peng L, Najam T, et al. Monodispersed Co in mesoporous polyhedrons: Fine-tuning of ZIF-8 structure with enhanced oxygen reduction activity. Electrochim Acta, 2017, 251: 498-504

63 Zhang L, Shi L, Huang L, et al. Rational design of high-performance $\mathrm{DeNO}_{x}$ catalysts based on $\mathrm{Mn}_{x} \mathrm{Co}_{3-x} \mathrm{O}_{4}$ nanocages derived from metalorganic frameworks. ACS Catal, 2014, 4: 1753-1763

64 Ge L, Yang Y, Wang L, et al. High activity electrocatalysts from metal-organic framework-carbon nanotube templates for the oxygen reduction reaction. Carbon, 2015, 82: 417-424

65 Zhu Z, Chen C, Cai M, et al. Porous Co-N-C ORR catalysts of high performance synthesized with ZIF-67 templates. Mater Res Bull, 2019, 114: $161-169$

66 Xuan C, Hou B, Xia W, et al. From a ZIF-8 polyhedron to three-dimensional nitrogen doped hierarchical porous carbon: An efficient electrocatalyst for the oxygen reduction reaction. J Mater Chem A, 2018, 6: 10731-10739

67 Zhang P, Sun F, Xiang Z, et al. ZIF-derived in situ nitrogen-doped porous carbons as efficient metal-free electrocatalysts for oxygen reduction reaction. Energy Environ Sci, 2014, 7: 442-450

68 Pandiaraj S, Aiyappa H B, Banerjee R, et al. Post modification of MOF derived carbon via $g-\mathrm{C}_{3} \mathrm{~N}_{4}$ entrapment for an efficient metal-free oxygen reduction reaction. Chem Commun, 2014, 50: 3363-3366

69 Li J, Chen Y, Tang Y, et al. Metal-organic framework templated nitrogen and sulfur co-doped porous carbons as highly efficient metal-free electrocatalysts for oxygen reduction reactions. J Mater Chem A, 2014, 2: 6316-6319

70 Li J S, Li S L, Tang Y J, et al. Heteroatoms ternary-doped porous carbons derived from MOFs as metal-free electrocatalysts for oxygen reduction reaction. Sci Rep, 2015, 4: 5130

71 Zhang L, Wang X, Wang R, et al. Structural evolution from metal-organic framework to hybrids of nitrogen-doped porous carbon and carbon nanotubes for enhanced oxygen reduction activity. Chem Mater, 2015, 27: 7610-7618

72 Liu K, Kattel S, Mao V, et al. Electrochemical and computational study of oxygen reduction reaction on nonprecious transition metal/nitrogen doped carbon nanofibers in acid medium. J Phys Chem C, 2016, 120: 1586-1596

73 Ding L, Tang T, Hu J S. Recent progress in proton-exchange membrane fuel cells based on metal-nitrogen-carbon catalysts. Acta Physico Chim Sin, 2021, 37: 2010048

74 Banham D, Kishimoto T, Sato T, et al. New insights into non-precious metal catalyst layer designs for proton exchange membrane fuel cells: 
Improving performance and stability. J Power Sources, 2017, 344: 39-45

75 Shen S, Chen J, Yan X, et al. Insights into properties of non-precious metal catalyst (NPMC)-based catalyst layer for proton exchange membrane fuel cells. J Power Sources, 2021, 496: 229817

76 Chen J, Yan X, Fu C, et al. Insight into the rapid degradation behavior of nonprecious metal Fe-N-C electrocatalyst-based proton exchange membrane fuel cells. ACS Appl Mater Interfaces, 2019, 11: 37779-37786

\title{
Progress in non-noble metal oxygen reduction electrocatalysts based on MOFs
}

\author{
REN ZiWen ${ }^{1}$, TAN ZeHao ${ }^{1}$, XIANG SiLei ${ }^{1}$, CHEN ShiQu $^{1}$, SHEN ShuiYun ${ }^{1,2} \&$ \\ ZHANG JunLiang ${ }^{1,2}$ \\ ${ }^{1}$ Institute of Fuel Cells, School of Mechanical Engineering, Shanghai Jiao Tong University, Shanghai 200240, China; \\ ${ }^{2}$ MOE Key Laboratory of Power \& Machinery Engineering, Shanghai Jiao Tong University, Shanghai 200240, China
}

Proton exchange membrane fuel cells (PEMFCs) are favored in the field of new energy vehicles because of their cleanliness, high efficiency, quietness, high power density, low operating temperature, fast start-up and power matching. With the realization of mass production of fuel cell vehicles in many countries in the world in recent years, its large-scale promotion is imperative. However, the PEMFC cathode uses a high-load platinum $(\mathrm{Pt})$-based catalyst, which has greatly hindered the commercialization of fuel cell vehicles because of high cost. Pt is the most effective electrocatalyst for the low-temperature fuel cell cathode oxygen reduction reaction (ORR). On one hand, it can greatly reduce the amount of Pt through alloying and single-atom layer design. On the other hand, it can develop alternative high-activity and high-stability non-noble metals. The catalyst process is considered the ultimate solution. Among the many types of non-noble metal catalysts, the ORR activity and lifetime of the carbon-nitrogen-transition metal series non-noble metal catalysts are particularly worthy of attention. Non-precious metal ORR electrocatalysts based on metal organic framework materials (MOFs) have been extensively studied for their excellent properties. This paper introduces the characteristics and advantages of MOFs materials in detail and reviews the research status of carbon-nitrogen-transition metal ORR electrocatalysts based on MOFs materials at home and abroad in recent years, including Fe-based MOFs catalysts, Co-based MOFs catalysts, and bimetal MOFs catalysts. It also analyzes and forecasts the bottlenecks and challenges encountered in the research. In the future, we need to conduct in-depth research on the activity and stability of membrane electrodes.

fuel cells, catalyst, oxidation, metal organic frameworks, proton exchange membrane

doi: 10.1360/SST-2021-0162 